\title{
Pengembangan Sistem Komunikasi Data Dan Jaringan Komputer Dengan Penerapan Wireless Distribution System (WDS) di SMK Negeri 1 Pringgabaya
}

\author{
M. Nuzuluddin \\ Program Studi Teknik Komputer, Universitas Hamzanwadi \\ *mnuzzuludin@hamzanwadi.ac.id
}

\begin{abstract}
Abstrak
Pada saat ini, banyak sekolah telah memakai jaringan nirkabel yang digunakan untuk mendukung jaringan yang menggunakan kabel. Jaringan kabel digunakan sebagai penguat dari access point untuk menjadikan akses internet bagi pengguna. Permasalahan dari pada jaringan yang menggunakan kabel ini dapat menjadi masalah yang besar bagi tempat yang sulit dibentangkan kabel, sehingga dapat mengurangi fleksibelitas pemakaian. Oleh karena itu, dengan mengembangkan sistem Wireless Distribution System (WDS) unntuk AP (Access Point) diharapkan dapat menyelesaikan permasalahan yang terjadi ada jaringan komputer yang menggunakan kabel. WDS adalah suatu sistem yang digunakan untuk membangun jaringan internet dengan wireless atau nirkabel (tanpa kabel) yang digunakan sebagai backbone dari AP dengan memanfaatkan lajur jaringan tanpa kabel dari AP tersebut. Parameter yang digunakan dalam sistem WDS adalah parameter throughput, jitter, delay dan packet loss. Kualitas kerja sistem WDS ini dapat dianalisa sehingga dapat mengetahuai perbandingan hasil kinerja AP (AccessPoint) dengan menggunakan jaringan backbon yang berkabel..
\end{abstract}

Kata Kunci : AP (Access Point), WDS, Jaringan Wireless

\begin{abstract}
At Present, many schools have used wireless networks that are used to support wired networks. Cable network is used as an amplifier of access point to make internet access for users. The problems of networking using these cables can be a major constraint to inaccessible places that can reduce the flexibility of usage. The solution for this problem is to develop and implement Wireless Distribution System (WDS) on the access point. WDS is a system to develop wireless internet network without having to use cable as backbone for access point but to take advantage of wireless network path from access point. The parameters used in the WDS system are the parameters of jitter, througput, delay and packet loss. WDS performance can be analyzed so that will be known comparison of access point performance results with cable backbone.
\end{abstract}

Keyword: AP (Access Point), WDS, Wireless Network

\section{Pendahuluan}

Di era informasi seperti saat ini, kehadiran teknologi tidak bisa dipungkiri oleh manusia. Hampir disemua sisi kehidupan seperti bidang ekonomi, pendidikan, pertahanan keamanan maupun bidang lainnya sangat di pengaruhi oleh teknologi. Apalagi sekarang ini pesatnya perkembangan Teknologi Informasi dan Komunikasi dengan penciptaan teknlogi terbaru baik berupa bentuk, ukuran, kemampuan dan kecepatannya. Sehingga pada dasarnya hal inilah yang membawa perubahan besar bagi kehidupan. Pada dasarnya komputer hanya bisa digunakan secara individual (sendiri-sendiri). Akan tetapi dengan perkembangan teknologi yang pesat, memungkinkan komputer untuk berinteraksi dengan komputer lain dengan menggunakan kabel dan port komunikasi, dua 
buah komputer atau lebih dapat dikomunikasikan dan saling bekerjasama. Seandainya dua komputer (KA dan KB) dihubungkan, maka halhal yang dapat dilakukan antara lain: File-file yang ada pada komputer KA dapat diakses oleh komputer KB, begitu jugas sebaliknya disk drive Komputer KB dapat diakses dari Komputer KA, data yang ada pada komputer KA dapat di kirim ke komputer KB, dan lain sebagainya.

Dengan prinsip yang telah dijelaskantersebut, maka suatu jaringan komputer dapat dikembangkan, dimana dalam jaringan tersebut terhubung lebih dari satu buah komputer sehingga antar komputer tersebut dapat saling tukar menukar informasi dan data. Untuk dapat membuat beberapa komputer terhubung dengan jaringan sehingga dapat bekerjasama, dibutuhkan media transmisi baik berupa penggunaan kabel (terstrial) maupun tanpa kabel (melalui satelit). Kabel transmisi digital (misalnya dengan jenis UTP); Perangkat lunak sistem operasi yang mempunyai aplikasi dengan fitur jaringan yang diinstalasi pada masing-masing komputer.

Jaringan dengan tanpa menggunakan kabelatau wireless (nirkabel) merupakan solusi terbaik dalam membangun dan mengembangkan sebuah jaringan komputer yang fleksibel dan praktis [1]. Saat ini sebagian besar akses publik seperti kantor, café, taman, perkantoran dan sekolahsekolah dilengkapi dengan fasilitas hotspot agar para pengunjungnya dapat menikmati layanan internet secara wireless atau nirkabel dengan praktis. Selain daripada itu pada beberapa instansi perkantoran dan sekolah juga menggunkan jaringan nirkabel ini sebagai pendukung jaringan kabel yang sudah ada. Namun pada penerapannya masih menggunakan jaringan kabel sebagai backbone dari access point agar client yang terkoneksi bisa dengan mudah mengakses internet. Masalah dari jaringan kabel ini adalah dapat menjadi kendala yang besar bagi tempat yang rumint terjangkau dengan kabel sehingga dapat mengurangi fleksibelitas pemakaian atau akses.

Solusi dari permasalahan tersebut adalah dengan menerapkan Wireless Distribution System (WDS) dari perangkat AP (access point). WDS merupakan sistem untuk mengembangkan jaringan internet tanpa harus menggunakan kabel (nirkabel) sebagai backbone dari access point [2]. Dengan demikian tujuan dari hal tersebut adalah tidak lain hanya untuk memanfaatkan jalur nirkabel dari access point tersebut.

Pada era informasi seperti sekarang ini profesi guru merupakan profesi yang sangat penting, yang tugas pokoknya adalah mengajar. Disisi lain dari bukunya, Dalam masyarakat informasi pada lembaga sosial kuncinya adalah research university, hal ini yang punya peranan penting dalam masyarakat sebagaimana pabrik baja dalam masyarakat industri dan sawah serta ladang dalam masyarakat pertanian [3]. Dengan 
demikian betapa pentingnya peranan sistem pendidikan (sekolah, guru, semua ini merupakan bagian-bagian penting sistem pendidikan) pada era informasi mendatang. SMK Negeri 1 Pringgabaya merupakan salah satu lembaga pendidikan swasta yang sangat memperhatikan kinerja gurunya dan dalam sistem informasi sudah menggunakan sistem komunikasi data dan jaringan komputer yang cukup baik. Oleh karena itu dibutuhkan pengembangan sarana dan prasana yang mendukung sistem komunikasi data dan jaringan komputer untuk mengembangkan sistem pendidikan yang ada pada SMK Negeri 1 Pringgabaya. Pada Saat ini, jaringan pada SMK Negeri 1 Pringgabaya menggunakan jaringandengan topologi Based Server/ sarana dan rasarana Wireless. Artinya pada SMK Negeri 1 Pringgabaya digunakan perangkat Access Point menjadi server yang melayani akses jaringan Wi-Fi untuk komputer pemakai (client).

Dengan kondisi seperti ini, maka perlu melakukan pengembangan terhadap jaringan yang menggunakan perancangan Wireless Distribution System (WDS). Untuk merealisasikan hal tersebut, maka ditulislah artikel yang berjudul "Pengembangan Sistem Komunikasi Data Dan Jaringan Komputer Dengan Penerapan Wireless Distribution System (WDS) Di SMK Negeri 1 Pringgabaya

\section{Tinjauan Pustaka}

\subsection{Penelitian Terkait}

Penelitian menggunakan empat buah AP yang terhubung secara point to point dengan jarak masing-masing 30 meter. Pada penelitian tersebut dihasilkan Throughput maksimal dari AP-1 ke AP-2, AP-1 ke AP-3, AP-1 ke AP- 4 semakin turun disebabkan bandwidth yang terbagi. Nilai rata-rata Jitter terus meningkat dan masih diambang batas yang diizinkan yaitu 0 100 ms baik pada WDS-1, WDS-2, dan WDS-3 pada 1 client. Nilai rata-rata packet loss pada masing-masing WDS-1, WDS-2, dan WDS-3 masih dalam kategori bagus. Dari hasil pengujian berdasarkan jarak, semakin jauh jarak antar AP maka Bandwidth yang dikirim terbagi dan hasil throughtput semakin kecil [4].

Penelitian terkait lainnya yaitu optimasi ketinggian AP pada jaringan WDS. Pada penelitian tersebut kualitas layanan yang diukur adalah throughput dan delay. Perancangan meliputi konfigurasi WDS dan FTP server. Pengujian dilakukan di dalam dan luar ruangan dengan variasi ketinggian $A P \quad 0,75$ meter, 2 meter, 3,5 meter, dan 4 meter. Pengujian tersebut menghasilkan ketinggian optimal AP di dalam ruangan yaitu pada ketinggian 2 meter dengan throughput ratarata sebesar 169,08 Bps, sedangkan posisi optimal AP di luar ruangan yaitu pada ketinggian 0,75 meter dengan throughput 676,08 
Bps [5].

Penelitian analisa kinerja implementasi Wireless Distribution System pada perangkat Access Point 802.11G menggunakan Openwrt menggunakan dua buah AP dan variasi jumlah client sebanyak 1 (satu) hingga 12 (dua belas) client. Pengujian dilakukan sebanyak 10 (sepuluh) kali pada kondisi LoS dan Nlos. Dari hasil pengujian dengan banyak client terdapat satu atau dua buah client yang hanya mendapatkan sebagian kecil dari kanal yang ada. Pada kondisi LoS jaringan dengan sistem WDS memiliki pengaruh yang kecil terhadap penurunan kualitas Throughput yang diterima oleh client. Sedangkan pada kondisi NloS pada ruangan yang terpisah tembok tebal dapat menurunkan kualitas Throughput rata-rata yang diperoleh client hingga sebesar $42 \%$ dari kondisi LoS. [6].

\subsection{Landasan Teori}

Segala bentuk permasalahan pada komunikasi data mengharuskan seluruh aturan harus berkomunikasi dan bekerja sama secara baik antara data yang satu dengan yang lain. Sekumpulan peraturan tersebut digunakan sebgai pengatur proses pengiriman data, hal ini sering disebut sebagai protokol komunikasi data. Dan biasanya protokol ini digunakan dalam bentuk aplikasi software (perangkat lunak atau program komputer) yang ada pada peralatan komunikasi data dan komputer lainnya. Ada beberapa kumpulan protokol dirancang atau didesain untuk melakukan komunikasi data pada Wireless Area Network (WAN) disebut TCP/IP. Protokol pada TCP/IP ini bertanggung jawab ataskomunikasi data pada bagiannya masingmasing. Oleh karena itu, tugas masing-masing protokol menjadi sederhana dan jelas. Sehingga protokol yang satu tidak perlu mengetahui cara kerja protokol yang lainnya, selama masih dapat mengirim data atau transfer data antar komputer. Protokol merupakan standar aturan yang mengizinkan dan mengatur terjadinya komunikasi atau transfer data antara dua komputer atau lebih [7]. Oleh sebab itu, protokol yang deminkian bisa diterapkan pada hardware (perangkat keras) dan perangkat lunak (software) atau bisa terkombinasi antara keduanya. Ada tiga hal yang harus dipertimbangkan dalam membuat protokol, yaitu efektivitas, kehandalan, dan Kemampuan dalam mengatasi kondisi gagal di jaringan (network). Jaringan komputer merupakan hubungan atau "interkoneksi" antar dua komputer atau lebih yang saling terhubung dengan baik, baik menggunakan jaringan tanpa kabel atau nirkabel (wireless) maupun jaringan yang menggunakan media kabel [8]. Dua unit komputer dikatakan telah terkoneksi apabila keduanya bisa melakukan komunikasi data/bertukarinformasi, berbagi sumber (resource) yang dimiliki, seperti: 
printer, file, media penyimpanan (hardisk, flashdisk, dII).

Jaringan nirkabel (tanpa kabel atau Wireless LAN) atau biasa disingkat dengan WLAN merupakan sebuah sistem yang digunakan untuk bertukar informasi atau komunikasi data yang elastis atau fleksibel serta pengaplikasiannya dapat sebagai ekstensi maupun pilihan alternatif pengganti untuk jaringan LAN yang menggukan media kabel. Sedangkan WLAN menggunakan teknologi frekuensi radio untuk melakukan komunikasi (mengirim dan menerima) data melalui media udara, dengan meminimalisasi kebutuhan akan sambungan kabel [9]. Dengan demikian, antara konektivitas data dan mobilitas pengguna (user) pada WLAN dapat dikombinasikan. Oleh karena itu, WLAN merupakan salah satu alternatif untuk LAN (dengan kabel) sulit atau tidak mungkin untuk dibangun. Diagram struktur WLAN dapat digambarkan pada gambar 1 berikut ini.

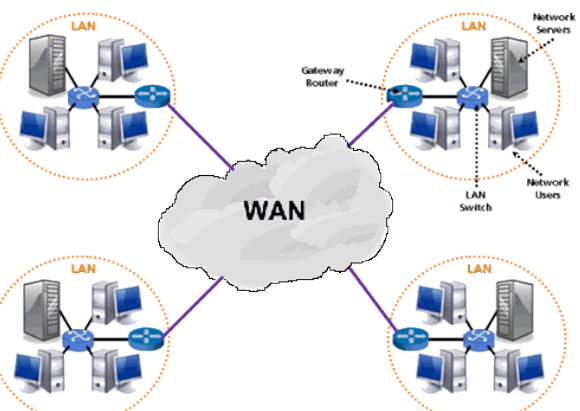

Gambar 1. Wide Area Network (WAN)

\subsection{Tahapan Penelitian}

Pada artikel ini digunakan pendekatan model Network Development Life Cycle (NDLC). Model NDLC dapat digambarkan seperti pada gambar 2 berikut:

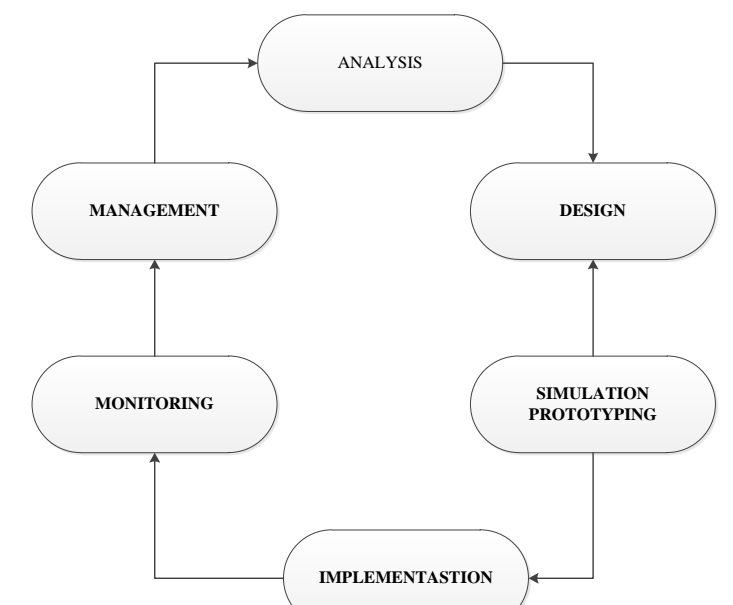

Gambar 2. Pengembangan Model Network Development Life Cycle (NDLC).

NDLC dapat didefinisikan sebagai suatu model dengan siklus proses perancangan atau pengembangan suatu sistem jaringan komputer. Pada model NDLC terdapat elemen yang mendefinisikan tahapan atau mekanisme proses yang spesifik. Kata cycle merupakan kunci yang bersifat deskriptif dari siklus yang berkelanjutan, maka dalam pengembangan sistem jaringan, model NDLC dapat menggambarkan secara keseluruhan proses dan tahapan pengembangan sistem jaringan secara berkesinambungan atau berkelanjutan.

Dari paparan diatas, NDLC dapat dijadikan sebagai metode yang bisa dijadikan acuan (secara keseluruhan atau secara garis besar) pada proses perancangan dan pengembangan sistem jaringan komputer. Oleh karena itu dalam 
artikel ini digunakan model NDLC sebagai metode perancangan dalam pengembangan jaringan komputer yang ada di SMK Negeri 1 Pringgabaya. Dikarenakan model NDLC ini merupakan suatu proses dalam komunikasi data atau pertukaran informasi yang menggambarkan dari awal siklus dan akhir dalam membangun sebuah jaringan komputer [11].

\section{Metode Penelitian}

Untuk mendapatkan data dan informasi yang dibutuhkan ada beberapa cara yang penulis lakukakan untuk mendapatkan data dan informasi yang benar dan jelas yaitu sebagai berikut:

\section{a. Data Primer}

Data dikumpulkan secara langsung dari objek yang diteliti. Adapun cara-cara yang dipakai untuk mengumpulkan data tersebut adalah sebaga berikut:

1) Observasi (Pengamatan Langsung)

Pengamatan dalah sebuah metode pengumpulan data dengan cara melakukan pencatatan langsung (observasi) pada SMK Negeri 1 Pringgabaya.

2) Dokumentasi

Metode dokumentasi merupakan metode untuk mengumpulkan data dengan cara membaca buku-buku literatur dan dokumendokumen yang berhubungan dengan topik artikel [10].

\section{b. Data Sekunder}

Data skunder didapatkan untuk dapat digunakan. Data skunder dapat berupa suatu pengetahuan teorotis, baik dari bahan-bahan kuliah, bukubuku referensi yang relevan, serta dari hasil penjelajahan (browsing) di internet yang relevan dengan pembahasan.

\section{Hasil dan Pembahasan \\ a. Hasil}

Pada saat observasi didapatkan hasil bahwa SMKN 1 Pringgabaya adalah sekolah dibawah naungan pemerintah provinsi Nusa Tenggara Barat bergerak di bidang pendidikan untuk memberikan layanan pendidikan kejuruan pada bidang keahlian: a) Teknologi dan rekayasa, dan b) Teknologi Informasi dan Komputer. Pada saat ini SMK Negeri 1 Pringgabaya telah menggunakan topologi based server / sarana dan prasarana jaringan wireless. Dengan penggunaan perangkat $A P$ sebagai server yang melayani pengguna (user) sebagai komputer client untuk akses jaringan Wi-Fi. Penggunaan IT untuk tujuan akademik sudah bagus, management masih tahap awal, branding school juga sudah maksimal melalui website, sosmed dan blog guru yang ada. SMK Negeri 1 Pringgabaya memiliki topologi jaringan yang sama setiap gedung, dengan menggunakan topologi setiap ruangan yang ada komputernya terutama pada lab komputer, dan jaringan 
kesetiap ruangan menggunakan topologi star. Topologi jaringan yang digunakan terlihat seperti gambar 3.

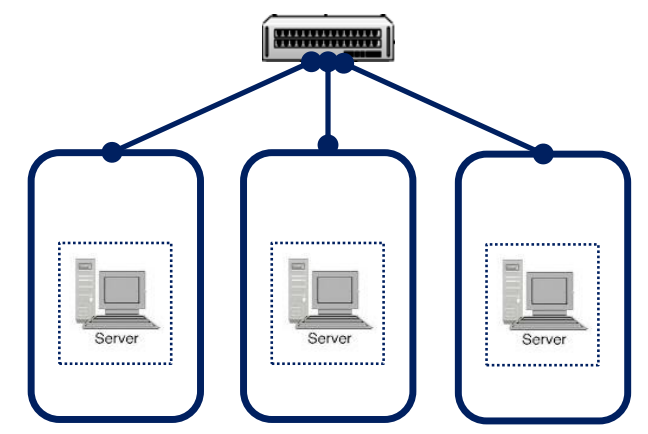

Gambar 3. Skema Topologi Jaringan SMKN 1 Pringgabaya

Selain data topologi jaringan diatas berdasarkan hasil observasi juga di dapat identifiakasi perangkat yang di gunakan dalam melakukan komunikasi data pada jaringan komputer. Yaitu seperti tertera dalam tabel 1.

Dalam rangka meningkatkan layanan terhadap siswa, guru dan staf serta stakeholder yang terkait, maka diperlukan dibangun atau dikembangkan sarana dan prasarana jaringan komputer dengan mengintegrasikan semua layanan di SMK Negeri 1 Pringgabaya dengan baik. Dalam hal ini dibutuhkan juga pengembangan dan pembangunan sarana dan prasarana jaringan komputer untuk mendukung dalam penilaian akreditasi sekolah agar nilainya bisa meningkat. Karena pada kriteria penilaian dalam akreditasi sekolah salah satunya adalah kinerja sekolah, serta krireria penilaian untuk sekolah berupa sarana dan prasarana, serta efisiensi dalam menyelenggarakan pembelajaran di sekolah.
Hasil observasi di jelaskan juga bahwa motivasi dari manajemen sekolah pada SMK Negeri 1 Pringgabaya yang mendasari untuk membangun dan mengembangkan layanan jaringan komputer antara lain, sebagai berikut:

a. Untuk meningkatkan infrastruktur (sarana prasarana) yang mendukung dalam proses akreditasi agar bisa mendapatkan nilai yang lebih baik dan memuaskan;

b. Meningkatakan kinerja sekolah pada kegiatan belajar mengajar, dikarenakan akses informasi yang terus meningkatkan kebutuhan baik kebutuhan guru, karyawan, maupun siswa. Hal ini tentunya sangat membutuhkan sarana prasarana (infrastruktur) dalam rangakan melayani client pada layanan jaringan internet yang handal dan baik;

c. Strategi dalam berbisnis, bahwa menjadi kewajiban bagi institusi pendidikan untuk meningkatkan publisitas sarana dan prasarana yang dimiliki sekolah. Oleh karena itu, layanan informasi di SMK Negeri 1 Pringgabaya, lebih khususnya pada ranah layanan jaringan internet;

d. Dengan membangun dan mengembangakan jaringan antar laboratorium komputer yang terintegrasi dengan yang lainnya, diharapkan penelitian di bidang komputer, khususnya yang membahas tentang jaringan pada 
komputer dapat ditingkatkan kedepannya secara berkelanjutan.

Dari hasil observasi tersebut diatas, maka dalam hal ini sehingga dapat di rancang penegembangan dalam implementasi wireless Distribution System (WDS) menggunakan mikroTik Routerboard ini, maka didapat suatu hasil pengujian sistem untuk mengetahui apakah sistem telah berjalan sesuai yang diinginkan. Pengujian sistem dengan menggunakan sistem Wireless Distribution System (WDS) ini meliputi uji konektifitas terhadap sistem WDS itu sendiri, uji konektifitas masuk ke jaringan sekolah, uji konektifitas dengan menggunakan Ping Test, dan uji konektifitas dengan menggunakan Browser

\section{b. Pembahasan}

Topologi jaringan yang ada di SMK Negeri 1 Pringgabaya di gambarkan pada gambar 4 . Untuk pengembangannya digunakan topologi jaringan WDS.

Topologi WDS digunakan untuk menambah daya jangkau pancaran sinyal wifi yang dihasilkan oleh Access Point I. jarak yang bisa dijangkau oleh Access Point II mencapai 15 meter, begitu juga pada Access Point III. Sehingga jarak maksimum jaringan yang menggunakan WDS yaitu jarak pancar AP I ditambah dengan Jarak Pancar AP || dan AP III sehingga menjadi sejauh 45 Meter. Jarak ini mampu mencakup keseluruhan area sekolah yang ada di SMK Negeri 1 Pringgabaya. Gambar 5 adalah gambar topologi WDS yang digunakan untuk mengembangkan jaringan yang ada di SMK Negeri 1 Pringgabaya.

Dengan adanya jaringan WDS (Wireless Distribution System) akan mempermudah pengguna (user) untuk mengakses internet dengan mudah dalam cakupan sinyal yang lebih luas tanpa harus mengubah topologi jaringan yang sudah ada. Untuk perluasan jaringan WDS (Wireless Distribution System) ini tidak membutuhkan kabel sebagai penghubungnya. Sehingga penggunaan kabel dapat diminimalisir [2]. Selain dengan menerapkan WDS pada kondisi letak antar AP dalam kondisi N LoS di tempat yang dipisahkan oleh tembok dengan ukuran yang tebal dapat menurunkan kualitas kecepatan jaringan dengan rata-rata yang diperoleh klien sebesar $42 \%$ dari kondisi LoS, selain itu juga penurunan kualitas throughput semakin bertambah seiring meningkatnya jumlah pengguna (user) sebgai client yang terhubung. Oleh karena itu dengan adanya metode WDS dapat dilihat bahwa terjadi penurunan throughput dengan rata-rata sebesar $14.2 \%$ yaitu throughput pada jaringan tanpa menggunakan metode WDS dari sebesar $365.8 \mathrm{kbps}$ sampai pada jaringan dengan WDS sebesar $313 \mathrm{kbps}$ [6]. Sedangkan dengan menggunakan mode delay, jitter dan packet loss didapatkan nilai perbedaan yang tidak terlalu berpengaruh secara 
signifikan. Kondisi jarak antar AP pada jaringan komputer dengan sistem WDS mempunyai pengaruh yang besar terhadap kualitas throughput yang diterima oleh pengguna (user) sebagai client. Oleh karena itu, dengan menerapkan sistem WDS pada letak antar AP dalam kondisi tempat yang dipisahkan oleh tembok beton yang ukurannya tebal dapat juga membuat kualitas throughput jaringan turun. Selain itu penurunan kualitas jaringan seiring juga disebabkan oleh meningkatnya volume client yang terhubung.

Dari permasalahan tersebut diatas, maka slusinya adalah dengan memperluas cakupan area hotspot. Salah satu cara dalam memperluar cakupan area hotspot adalah dengan menambahkan Access Point menggunakan sistem WDS. Melihat topologi jaringan gedung, area jangkauan serta jarak koneksi yang kompleks menjadi alasan menggunakan jaringan Wireless Distribution System.

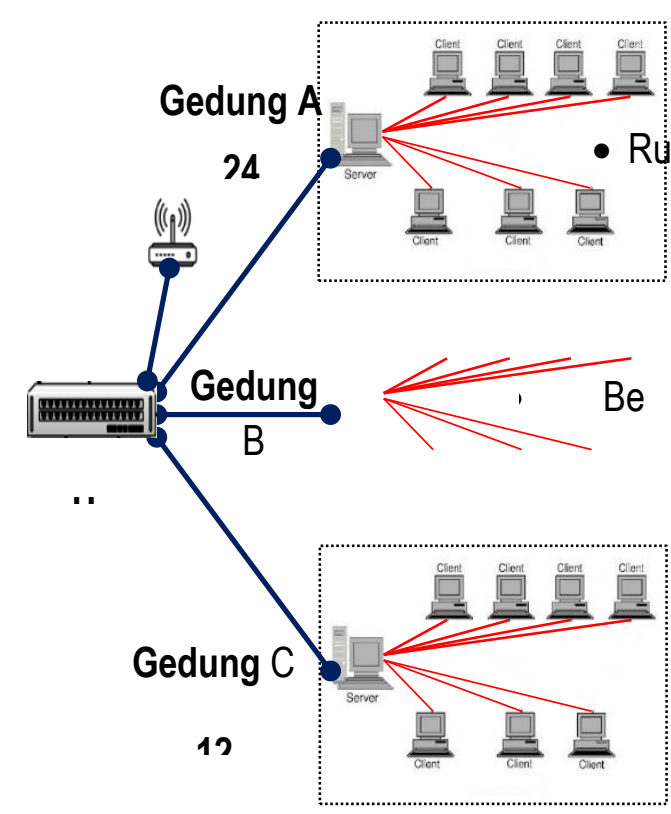

Gambar 4.Topologi Gedung Sekolah SMKN 1 Pringgabaya Alasan menggunakan sistem WDS sebagai solusi dari permasalahan kebutuhan data dan informasi adalah mempunyai nilai efisiensi biaya serta fleksibelitas penggunaan yang tinggi dalam pemeliharan dan pembangunan serta memanajemen jaringan. Oleh karena itu, berdasarkan telaah literatur diatas, maka dapat menjadi masukan bagi SMK Negeri 1 Pringgabaya untuk menggunakan jaringan dengan sistem WDS dalam mengembangan jaringan komputer yang ada di SMK. 


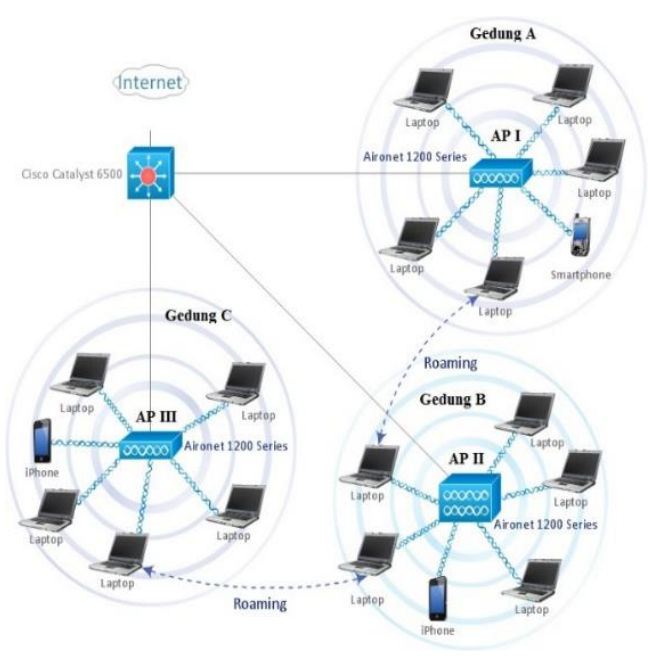

Gambar 5.Topologi WDS

sembarang tempat.

3. Penggunaan WDS sebagai solusi untuk interkoneksi perangkat wireless tanpa menggunakan kabel sebagai media transmisi penghubung adalah slusi tepat untuk koneksi mobile user secara bergerak.

4. Untuk perluasan jaringan WDS (Wireless Distribution System) ini tidak membutuhkan kabel sebagai penghubungnya. Sehingga penggunaan kabel dapat diminimalisir

\section{Kesimpulan}

Berdasarkan telaah literatur dilakukan dapat di simpulkan bahwa:

1. Penerapan metode Network Development Life Cycle (NDLC) mengembangkan suatu jaringan komputer diharapkan bisa cocok dalam meningkatkan strategi bisnis pada SMK Negeri 1 Pringgabaya di bidang pendidikan dalam mengimplementasikan infrastruktur jaringan. Karena NDLC yang memiliki enam tahap syang sistematis merupakan pedoman yang tepat sebagai acuan dalam pengembangan infrastruktur jaringan di SMK Negeri 1 Pringgabaya.

2. Penggunaan jaringan wireless sangatberguna dalam hal kemudahankonfigurasi setiap client dan, jaringan wireless berbasis WDS tidak memerlukan kabel utama atau backbone sehingga penempatan access point bisa di

\section{Daftar Pustaka}

[1] D. Setiawan, "Internetworking Development \& Design Life Cycle," UNSRI, 2009.

[2] H. Saputro, "Perancangan Dan Penerapan Wireless Distribution System (WDS) Pada Dinas Ketahanan Pangan Kabupaten Musi Rawas," Jusikom : Jurnal Sistem Komputer Musirawas Desember, vol. 1, no. 1, 2016.

[3] S. P. Roger, Rekayasa Perangkat Lunak (Pendekatan Praktis), Yogyakarta: Andi, 2012.

[4] S. Arif, "Analisis Kinerja Access Point 802.11g pada Jaringan Wireless Distribution System dari Sisi Client Menggunakan Topologi Point To Point," ETD Unsyiah, 2014.

[5] N. S. F, A. S. W and S. I, "Optimasi Ketinggian Access Point Pada Jaringan Wireless Distribution System," Transient, vol. 4, no. 2, 2015.

[6] L. A. P. D and S. K. A, "Analisa Kinerja Implementasi Wireless Distribution System Pada Perangkat Access Point 802 . 11 G," Politek Elektron. Institut Teknologi Sepuluh Nopember, pp. 1-6, 2011.

[7] L. Herlambang and A. Catur, Panduan 
Lengkap Menguasai Router Masa Depan

Menggunakan Mikrotik RouterOS,

Yogyakarta: Andi, 2008.

[8] S. Sukaridhoto, Jaringan Komputer, Surabaya: ITS , 2008.

[9] Akyildiz, Lan, Wang, Xudong, Wireless Mesh Networks, United Kingdom: John Wiley \& Sons Ltd, West Sussex, 2009.

[10] G. James E and R. Philip T, Third Edition, Applied Data Communications, A business-Oriented Approach, New York, 2001.

[11] S. Arikunto, Prosedur Penelitian: Suatu Pendekatan Praktek, Jakarta: Rineka Cipta, 2006..

[12] A. Sudianto and H. Ahmadi, "Rancang Bangun Sistem Informasi Penjualan Sparepart Motor Pada Bengkel Vinensi Motor Berbasis Web Guna Meningkatkan Penjualan dan Promosi Produk Pendahuluan Vinensi sepeda motor motor," Infotek J. Inform. dan Teknol., vol. 3, no. 2, pp. 32-39, 2020

[13] L. K. W. Sudianto Aris, Nurhidayati, "Penerapan Sistem Informasi Geografis Untuk Pemetaan Bengkel Tambal Ban di Kecamatan Selong Kabupaten Lombok Timur," Infotek J. Inform. dan Teknol., vol. 3, no. 1, pp. 51-57, 2020, doi: 10.1029/2019GH000237. 